\title{
KENNELLY-HEAVISIDE LAYER HEIGHT OBSERVATIONS FOR 4,045 AND 8,650 kc
}

\author{
By T. R. Gilliland
}

\section{ABSTRACT}

Virtual heights of the Kennelly-Heaviside layer as measured by the radio-echo method are reported for 4,045 and $8,650 \mathrm{kc}$. The report covers day time observations made each week between January 16 and June 19, 1930. Two evening tests are also described. Curves are given comparing heights with sunspot numbers and magnetic character. Records taken on April 28, 1930, the day of the solar eclipse, are shown.

This note is a report of results obtained by the echo method in the study of the Kennelly-Heaviside layer between January 16 and June 19, 1930. The method used is essentially that first used by Breit and Tuve ${ }^{1}$ and consists of the receiving and oscillographic recording of signals from a high-powered transmitter which is sending out pulses or "peaks" of extremely short duration with sufficient intervals of no emission between pulses to record the echoes. The time interval between the arrival of the ground wave and the first echo is used to calculate the "virtual height" .

The transmissions were furnished through the courtesy of the Naval Research Laboratory at Bellevue, D. C. Two $20 \mathrm{kw}$ crystalcontrolled transmitters were used, one operating on $4,045 \mathrm{kc}$ and the other on $8,650 \mathrm{kc}$, each being modulated by means of an unbalanced multivibrator circuit. ${ }^{3}$ The records were made at the National Bureau of Standards field station near Kensington, Md., at a distance of $21 \mathrm{~km}$ from the transmitter.

The results reported here were obtained from transmissions occurring each week on Mondays and Thursdays. The 4,045 kc was transmitted from 11.15 to $11.30 \mathrm{a} . \mathrm{m}$. and from 3.45 to $4 \mathrm{p}$. m., while the $8,650 \mathrm{kc}$ transmission was from 11.30 to $11.45 \mathrm{a} . \mathrm{m}$. and from 4 to 4.15 p. m., eastern standard time. On January 20 and 27, transmission was continued until midnight.

The curves in Figure 1 show morning and afternoon virtual heights for both frequencies. The curves are plotted with straight lines through the observed points. Usually more than one record was obtained during the 15 minutes of transmission on each frequency, so that most of the points on the curves represent averages of several readings. Considerable changes in height have been noted within a few minutes. On the morning of April 21, a change from 290 to 265 $\mathrm{km}$ was noted in seven minutes. (Fig. 2.) The interval between adjacent timing marks on each trace is $1 / 120$ second. The curves of Figure 1 show that on 4,045 kc the afternoon heights observed were always greater than the morning heights, but for $8,650 \mathrm{kc}$ this is 
not true. It is of interest to note that $8,650 \mathrm{kc}$ echoes were received only between February 6 and April 7. Except for this period, observations showed only the ground wave. During this time, however, the appearance of the echo pattern obtained on this frequency was usually similar to that for $4,045 \mathrm{kc}$, except for the much greater retardation on the higher frequency. As many as five distinct echoes have been recorded from a single transmitted pulse. One peculiarity that has been noted at times in the pattern on both frequencies is the appearance of the last of a group of multiple eachoes with greater amplitude than that of one or more of those preceding. Besides the layer for which the curves are drawn, a lower layer has

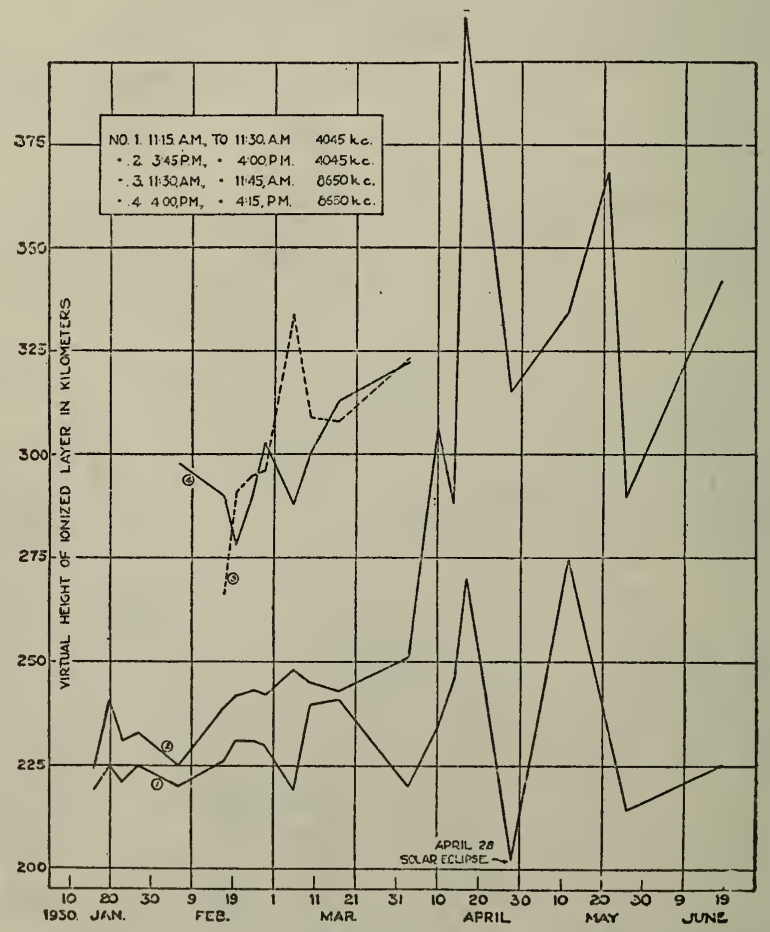

FIGURE 1.-Morning and afternoon virtual heights of the ionized layer for 4,0,45 and 8,650 kc, between January 16 and June 19, 1930

been observed on $4,045 \mathrm{kc}$ on a few occasions, at a height of about $120 \mathrm{~km}$. In Figure 3 are shown two records taken on January 23. In the lower record a weak echo peak giving a height of approximately $119 \mathrm{~km}$ appears between the ground peak and the strong echo peak from the $235 \mathrm{~km}$ layer. Following the latter peak are two smaller ones, the first of which appears to be a multiple reflection from the low layer, and the second from the high layer. The upper record, taken eight minutes later, shows a much stronger reflection from the low layer. That multiples do not follow the reflection from the high layer may be attributed to the obscuring of the high layer by the lower one. 
B. S. Journal of Research, RP246

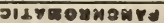
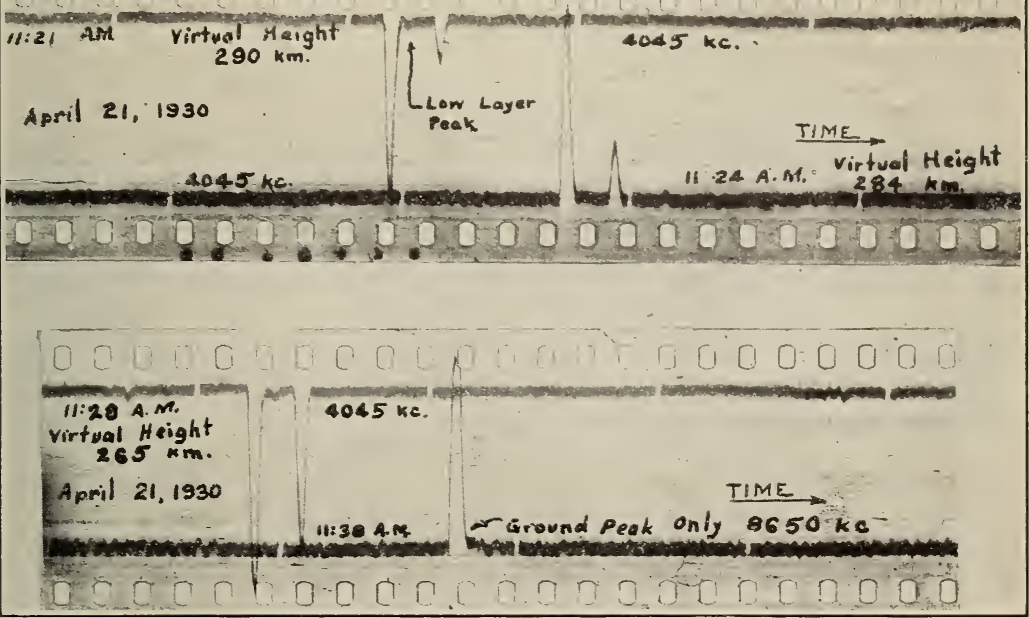

FIGURE 2 (retouched).-Records showing rapid change in height. First three traces show drop from 290 to $265 \mathrm{~km}$ in seven minutes for 4,045 $\mathrm{kc}$

Trace at bottom shows one single peak for $8,650 \mathrm{kc}$.

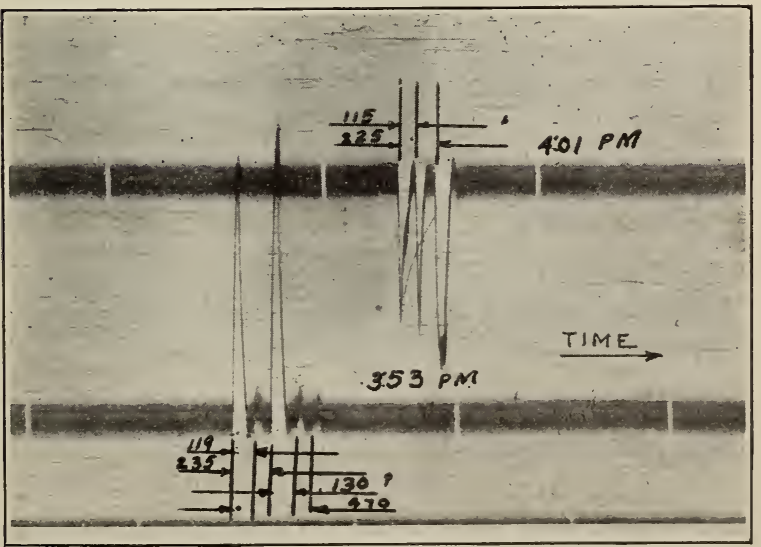

FigURE 3 (retouched).-4,045 kc transmission showing reflections from low layer, January 23, 1930 


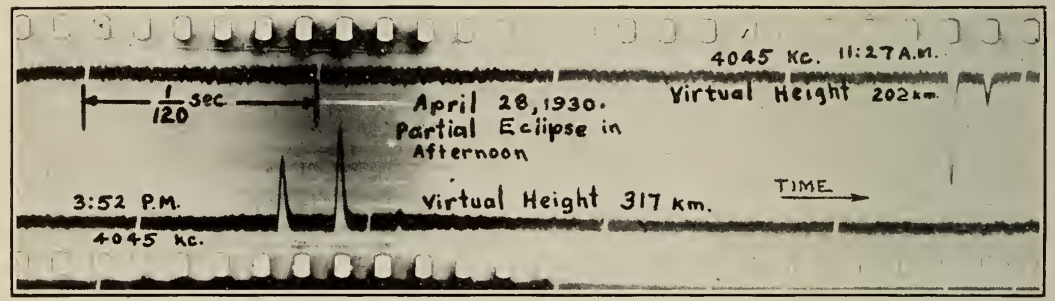

FIgURE 4.-4,045 kc transmission as recorded on day of solar eclipse, A pril 28 , 1930

Eclipse maximum 0.49 total at Washington at $3.23 \mathrm{p} . \mathrm{m}$.

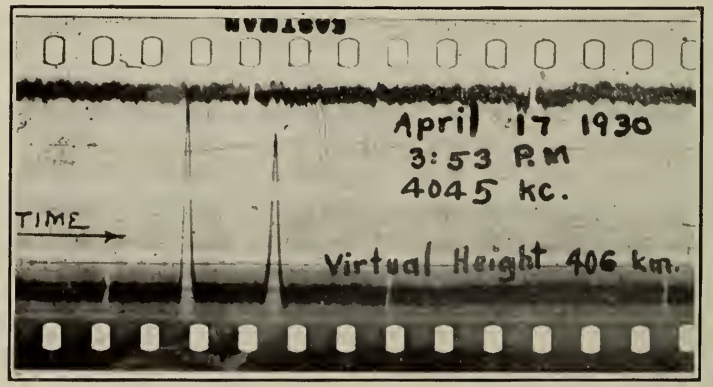

Figure 6.-Record showing virtual height of $406 \mathrm{~km}$ for 4,045 kc, April 17, 1930 
Records obtained on April 28, the day of the solar eclipse, give a morning height of only $202 \mathrm{~km}$ for $4,045 \mathrm{kc}$, which is considerably lower than any other value obtained during this series of observations. The lowest previous value was $219 \mathrm{~km}$ on January 16 . The eclipse did not reach a maximum, which was 0.49 total, until $3.23 \mathrm{p.} \mathrm{m}$. A record at $3.52 \mathrm{p}$. m. showed a height of $317 \mathrm{~km}$. (Fig. 4.)

The curves of Figure 5 were plotted to show possible correspondence

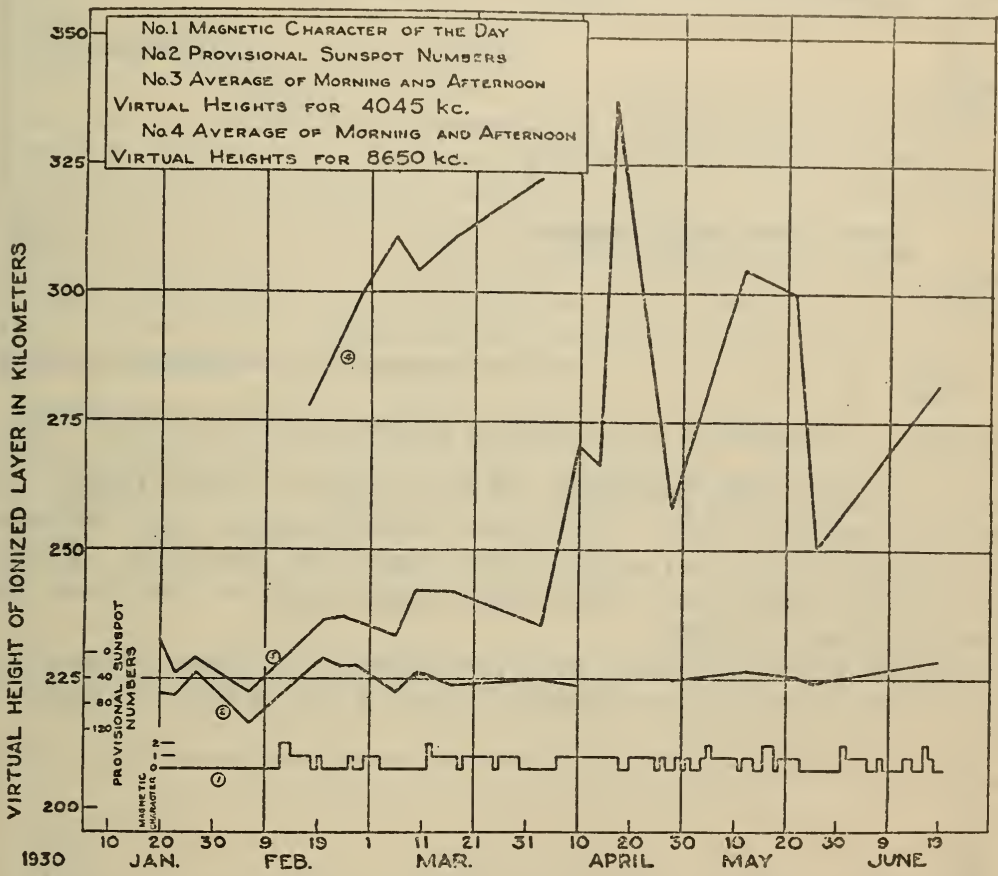

FIGURE 5.-Magnetic character of the day, sunspot numbers, and average virtual heights of ionized layer for 4,0.45 and 8,550 kc between January 16 and June 19, 1930

which virtual heights might bear to sun-spot numbers and to magnetic character. The curves of virtual height were plotted from averages of morning and aiternoon values. The sun-spot curve was plotted only for days on which measurements of height were made. Curve No. 1 shows the magnetic character of the day, zero representing a quiet day, while ordinates 1 and 2 represent moderate disturbance and severe disturbance, respectively. Although no conclusive correlation between magnetic character and height is evident from the curves, it will be noted that the disturbed period which began February 12 has been accompanied by a rise in height of considerable magnitude. The extreme heights (fig. 6) beginning about April 10, may suggest the disappearance of one layer, permitting a higher one to come into view rather than the rise indicated in the curves.

The existence of a close correspondence between sun-spot numbers and virtual heights for $4,045 \mathrm{kc}$, such as is suggested by curves 2 and 3 , Figure 5 , can be demonstrated only by observations over a much 
longer period. The correlation shown, while interesting is not considered in any sense conclusive, because of the limited duration of the available observations.

The curves of Figures 7 and 8 were plotted from data obtained when transmission was continued until midnight. In both cases heights are shown to fluctuate rapidly after dark. The dotted lines are

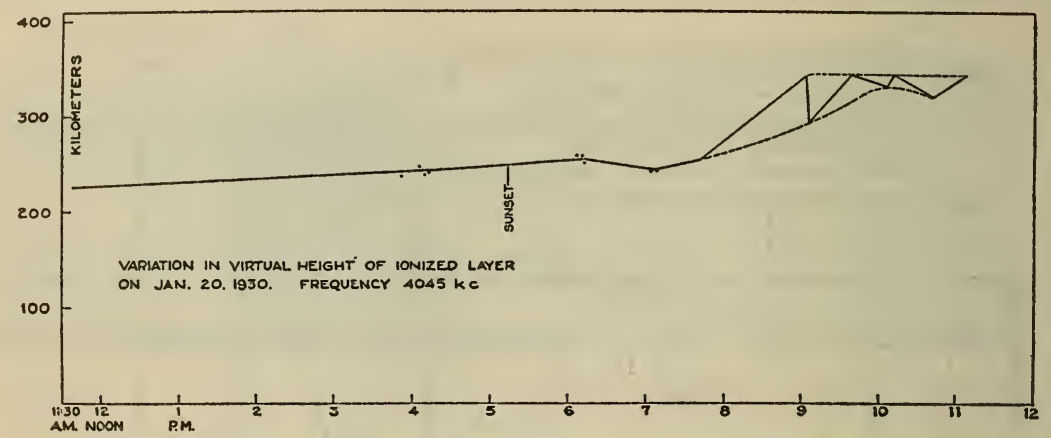

FIGURE 7.-Variation of virtual height of ionized layer on January 20, 1930

drawn to indicate the possibility of the existence of two layers, both of which rise after dark. The curves would suggest that reflections are occurring first from one layer and then from the other. Both of these evening tests show a dip after sunset, such as has been mentioned by other observers.

It will be noted that the curve for January 20 shows a maximum height of $344 \mathrm{~km}$ reached shortly after $9 \mathrm{p} . \mathrm{m}$., while the curve for

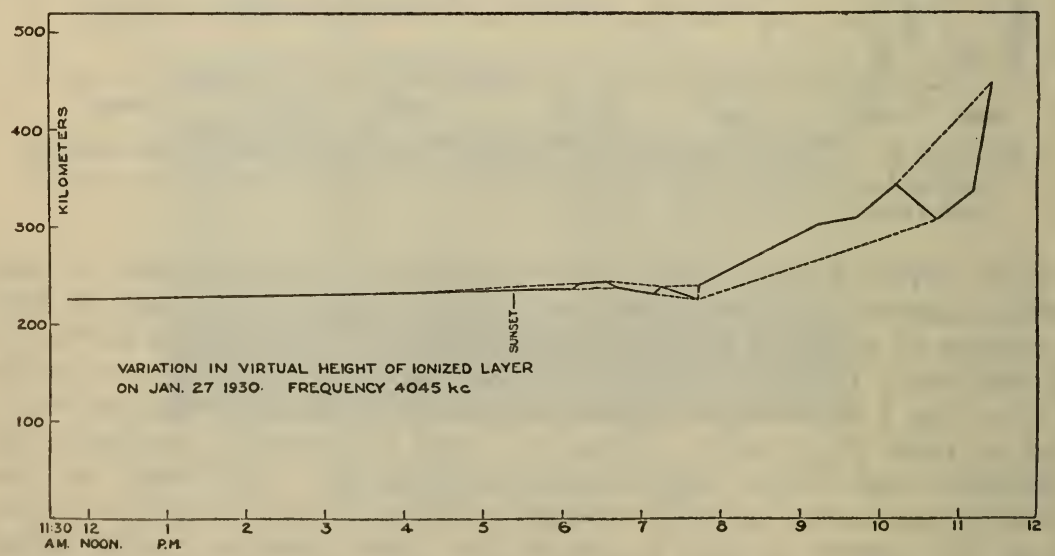

FiguRE 8.-Variation of virtual height of ionized layer on January 27, 1930

January 27 indicates no such "ceiling," but shows an increase up to $450 \mathrm{~km}$ at $11.41 \mathrm{p} . \mathrm{m}$. It may be of interest to note that the provisional sun-spot curve gives a value of 63 for January 20 and 31 for January 27.

Patterns obtained at night, especially during the early morning hours, are, in general, not as simple nor as easily interpreted as those 
obtained in the daytime. The reflections frequently appear as a number of irregular peaks or form one broad pulse. To interpret such records in terms of one, or even several, well-defined layers is extremely difficult. The results of such tests on other frequencies are reported in another paper recently published. ${ }^{4}$

During these observations it was not found practicable to monitor the transmitters to check the shape of the pulses sent out. In some cases the peaks were found to be split, but the character of the patterns was such that no appreciable errors could be introduced in the measurement of virtual heights.

In view of the fact that these observations have been carried on for so short a period of time and for such limited conditions, no attempt is made to give an interpretation of the results at this time. It is hoped that observations may be continued over a longer period of time and for a number of other frequencies.

Thanks are due to Dr. A. H. Taylor and assistants at the Naval Research Laboratory for furnishing the transmissions, to the Department of Terrestrial Magnetism for sun-spot data, and to the Coast and Geodetic Survey for magnetic data.

Washington, July 16, 1930.

1 P. A. de Mars, T. R. Gilliland, and G. W. Kenrick. Kennelly-Heaviside layer studies. Proc. I. R. E. 